University of Nebraska - Lincoln

DigitalCommons@University of Nebraska - Lincoln

2012

\title{
Measuring implicit psychological constructs in organizational behavior: An example using psychological capital
}

\author{
Peter D. Harms \\ University of Nebraska - Lincoln, pharms@gmail.com \\ Fred Luthans \\ University of Nebraska - Lincoln, fluthans1@unl.edu
}

Follow this and additional works at: https://digitalcommons.unl.edu/managementfacpub

Part of the Management Sciences and Quantitative Methods Commons

Harms, Peter D. and Luthans, Fred, "Measuring implicit psychological constructs in organizational behavior: An example using psychological capital" (2012). Management Department Faculty Publications. 85.

https://digitalcommons.unl.edu/managementfacpub/85

This Article is brought to you for free and open access by the Management Department at DigitalCommons@University of Nebraska - Lincoln. It has been accepted for inclusion in Management Department Faculty Publications by an authorized administrator of DigitalCommons@University of Nebraska - Lincoln. 
Published in Journal of Organizational Behavior 33:4 (May 2012), pp. 589-594; doi: 10.1002/job.1785

Copyright (C) 2012 John Wiley \& Sons, Ltd. Used by permission.

Submitted August 12, 2011; accepted November 26, 2012; published online February 6, 2012.

“THE INCUBATOR”

\title{
Measuring implicit psychological constructs in organizational behavior: An example using psychological capital
}

\author{
Peter D. Harms and Fred Luthans \\ Department of Management, University of Nebraska-Lincoln, Lincoln, Nebraska, USA \\ Corresponding author - Peter D. Harms, Department of Management, University of Nebraska-Lincoln, \\ Lincoln, Nebraska 68588-0491, USA; email pharms2@unl.edu
}

\begin{abstract}
Implicit psychological constructs are effective predictors of behavioral outcomes but are rarely used in organizational settings because of real or imagined problems with measurement validity and administration. To address these concerns, we present a means of assessing implicit constructs quickly and easily by using psychological capital as an example.
\end{abstract}

Keywords: implicit measures, implicit theories, psychological capital, positive organizational behavior, organizational behavior research methods

"It's not what you look at that matters, but what you see." - Henry David Thoreau

\section{Introduction}

The notion of implicit schemas and motives, conceived of as the unconscious drivers of behavior and decisions, has played an important role in understanding and measuring psychological constructs such as motivation, personality, and self-esteem. For example, Henry Murray and David McClelland pioneered the use of implicit measures such as the now famous Thematic Apperception Test (TAT) in their research on motivation, and self-esteem researchers have long used the Implicit Association Test. These implicit measures utilize a picture or a word phrase to have the respondent interpret or evaluate in a spontaneous, automatic, or unconscious manner, as opposed to the much more widely used explicit, self-report measures where the respondent answers specific questions in a more conscious, reflective manner. Moreover, respondents of implicit instruments are generally unaware of what construct is being measured. Although organizational behavior researchers have acknowledged the importance of implicit constructs in areas such as leadership, there has been comparatively little attention given to implicit measures.

The purpose of this "Incubator" is to stimulate interest and research activity in the development and validation of what we feel has been a missing link in important established and emerging organizational behavior implicit constructs - short, easy to use, and valid implicit measures. We use the now recognized positive organizational behavior construct of psychological capital (PsyCap) to demonstrate the development of such a new implicit measure that is easy to administer and interpret and provide beginning evidence of its validity. 


\section{Why Implicit Measures?}

Although there has been a very recent surge of renewed interest in the study of implicit measures among personality and attitudes researchers (e.g., see LeBel \& Paunonen, 2011), such measures are seldom found in the organizational behavior research literature (for some exceptions, see Bing, LeBreton, Davison, Migetz, \& James, 2007; Johnson \& Saboe, 2011; Latham, Stajkovic, \& Locke, 2010). A major stumbling block for organizational behavior researchers seems to be dissatisfaction with the suitability of implicit measures for applied settings. A number of reasons for this dissatisfaction have been suggested -including the complexity of scoring traditional implicit measures such as the TAT, the reported unreliability of many implicit measures, the lack of convergent validity with explicit measures, concerns about what construct is actually being measured, the difficulty of conducting such assessments in the workplace, and/or simply a lack of awareness of the research that has been carried out (LeBel \& Paunonen, 2011; Schultheiss, 2008).

Despite these potential problems with measuring implicit constructs, the potential interest in both the basic and applied fields comes from the fact that implicit psychological constructs have been linked with important outcomes that may be of interest to organizational researchers (e.g., leadership performance, leader emergence, conflict escalation and resolution, creativity, and health outcomes, Schultheiss, 2008). For instance, recent research using word-fragment completion tasks to assess implicit self-concepts demonstrated the predictive power of the implicit constructs for a variety of work performance outcomes above and beyond that of explicit measures (Johnson \& Saboe, 2011). Other researchers using perceiver effects as projective tests have demonstrated that implicit positive perceptions of others is associated with higher levels of organizational satisfaction, less cynicism, greater identification with their organization, and more positive peer-ratings of personality and popularity (Wood, Harms, \& Vazire, 2010).

Implicit and explicit measures of similar constructs often explain unique variance in important outcomes (Bing et al., 2007; McClelland, Koestner, \& Weinberger, 1989). However, implicit measures are believed to tap a more "authentic" psychological construct while at the same time being less susceptible to known problems with self-report measures such as socially desirable responding (Roberts, Harms, Smith, Wood, \& Webb, 2006). On the basis of these and other recent studies, there is reason to believe that the study and measurement of implicit constructs in organizational behavior is an underutilized but potentially rewarding path to pursue.

A particularly good example to demonstrate the efficacy of implicit measures for organizational behavior constructs is PsyCap. PsyCap is rooted in the wider positivity movement and is theoretically grounded in the idea that individuals who perceive situations in a more positive way will be more likely to flourish. Although Wood et al. (2010) were able to demonstrate that a positive worldview or mindset does have positive implications for organizational outcomes, the method they used to measure this implicit schema is likely prohibitive for most organizational researchers. Specifically, it involves getting multiple peer-ratings of randomly selected peers and averaging scores across them to remove target effects.

As an alternative, we propose that having participants simply rate imaginary others will be equally effective at eliciting implicit schemas. This approach immediately does away with obvious concerns about target effects, eliminates the need to have large groups of people who know one another, and reduces the time needed to elicit the implicit levels of positivity in general and PsyCap in particular. To demonstrate the potential benefits of using this type of implicit measure, we followed a brief overview of PsyCap by a description of the development of the new Implicit PsyCap Questionnaire (I-PCQ).

\section{Background on Psychological Capital}

The field of positive organizational behavior was first introduced in the Journal of Organizational Behavior about 10 years ago (Luthans, 2002; Wright, 2003) and has since received considerable attention through its major construct of PsyCap. PsyCap is a multidimensional construct consisting of hope, efficacy, resiliency, and optimism (i.e., the HERO within; see Luthans, Youssef, \& Avolio, 2007). Established in the positive psychology literature, hope is the belief or sense of agency that individuals can accomplish goals. Efficacy is the belief or confidence in one's own abilities to successfully execute and accomplish tasks. Resiliency reflects positive coping and bouncing back from adversity. Optimism is associated with making positive attributions and having positive expectations for future events. Taken together, these four psy- 
chological resources have the common thread of implicitly reflecting "one's positive appraisal of circumstances and probability for success based on motivated effort and perseverance" (Luthans, Avolio, Avey, \& Norman, 2007, p. 550).

A recent meta-analysis found that self-reported PsyCap is a significant predictor of a wide variety of individual-level organizational outcomes such as multiple measures of performance, attitudes such as satisfaction, commitment, and turnover intentions, and behaviors such as organizational citizenship and deviance (Avey, Reichard, Luthans, \& Mhatre, 2011). To date, virtually all research on PsyCap has made use of versions of a self-report measure of PsyCap, the Psychological Capital Questionnaire (PCQ; Luthans, Youssef et al., 2007, pp. 237-238). However, to answer the call for more use of heretofore little used implicit measures (e.g., see Becker, Cropanzano, \& Sanfey, 2011; Latham et al., 2010) and to meet the objectives of this "Incubator" section of the Journal of Organizational Behavior, as an example, we propose and validate a new implicit measure of PsyCap, the I-PCQ. More generally, we aim to provide a framework for developing new measures of implicit psychological constructs.

\section{Development and Validity Support of the Implicit Psychological Capital Questionnaire}

The purpose in developing and testing the I-PCQ is to demonstrate the utility to the Incubator audience of the implicit measurement approach not only for PsyCap but also for other organizational behavior constructs. More specifically, our objective is to introduce a method for developing new implicit measures that do not suffer from some of the problems associated with typical implicit measures (LeBel \& Paunonen, 2011). Our hope is that by demonstrating this process of developing a short and straightforward implicit measure, it will spur greater interest in the use of implicit measures in the wider field of organizational behavior.

In constructing our I-PCQ, we use a semi-projective technique using written prompts that are followed by normal, short questions scored along a Likert scale. To elicit implicit schemas related to positivity and PsyCap, we present respondents with three situational prompts, ask them to generate stories about someone (not themselves), and then have them respond to construct-targeted questions about the stories they generated. For clarification and for those who wish to use the I-PCQ, we include this implicit measure in Appendix A. This shows the instructions, the three story prompts, and the questions asked about each story.

As shown in the Appendix, one prompt presents a positive experience (i.e., "Someone has a new job"), one prompt presents a negative experience (i.e., "Someone makes a mistake at work"), and one prompt provides an ambiguous experience (i.e., "Someone talks to their supervisor"). The reason for having typically positive, negative, and ambiguous prompts is to provide a diversity of situational contexts with varying levels of difficulty that will facilitate response variation across items on the survey. Importantly, the ambiguous prompt is especially open to interpretation by the respondent. Such ambiguity is most similar to the classic Rorschach ink blots or TAT pictures that tend to be neutral in order for the respondents to project their personality or motives. This traditional approach, of course, takes more time and skill to interpret. However, the continuum of positive, neutral, and negative trigger terms on the I-PCQ with the same questions for each prompt greatly simplifies these time and interpretation problems.

Besides the three simple prompts, another important feature of the I-PCQ is that respondents are told to not actually write out their stories, just simply imagine them. Then for each of the positive, negative, and ambiguous stories, efficacy is assessed with item 8 "Feeling confident and self-assured in their ability," hope is assessed with item 2 "Believing that they can accomplish their goal," resiliency is assessed with item 7 "Believing that they can bounce back from any setbacks that have occurred," and finally, optimism is assessed with item 3 "Expecting good things to happen in the future." The remaining four items included in each of the three statements are fillers used to help disguise the intent of the measure. The three story prompts and questions were derived through unanimous agreement by the researchers and a panel of subject matter experts. These questions are answered using a 7-point scale (with anchors of $-3=$ the opposite is very true of this character, $0=$ irrelevant thought/feeling for this character, and $+3=$ very true of this character). Averaging the 12 items (the four PsyCap questions across the three stories) determined an overall PsyCap score. 


\section{Validity Analysis}

Although reporting the detailed statistical analysis is beyond the scope of this Incubator piece, we did find strong support for the validation of the I-PCQ (details can be obtained from the first author). The sample used in our analysis consisted of 278 employed adults from a wide variety of jobs and industries who volunteered to participate in university-sponsored research on the workplace. Besides the I-PCQ shown in Appendix A, the study participants also completed the self-report measure of psychological capital (PCQ-12; Luthans, Youssef et al., 2007), the Minnesota Satisfaction Questionnaire (Price \& Mueller, 1986), Williams and Anderson's (1991) individual and organizational citizenship behaviors questionnaire, the interpersonal deviance subscale of Bennett and Robinson's (2000) workplace deviance measure, and task performance was measured using Williams and Anderson's (1991) scale.

The internal reliability coefficient for the I-PCQ was high, as were all the other measures used in the analysis. In terms of convergent and discriminant validities, the I-PCQ scores were significantly correlated with the established self-report PCQ- 12, but this correlation was also low enough to indicate discriminant validity. Moreover, both the I-PCQ and PCQ-12 measures were significantly correlated with each of the major work attitudinal, behavioral, and performance outcome measures.

To evaluate whether the I-PCQ adds any meaningful predictive power above and beyond the traditional PCQ self-report measure of PsyCap, we entered the I-PCQ after the PCQ in multiple regression equations predicting the work outcomes. In each case, the I-PCQ not only significantly predicted the performance and satisfaction outcomes beyond the effects of the PCQ measure of PsyCap, but the addition of the I-PCQ to the model also significantly improved the amount of variance explained in the criteria. Thus, the analysis indicated that not only does the I-PCQ measure of PsyCap indicate convergent and discriminant validity vis-à-vis the PCQ but that the I-PCQ also is a significant predictor of both positive and negative work outcomes and explains variance in these outcomes beyond the effects of the traditional self-report measure of PsyCap.

\section{Demonstrating the Value of Implicit Measures}

Although once again popular among personality psychologists, organizational behavior researchers still largely ignore implicit measures and their relationship to important work outcomes. We submit that implicit measures can add considerable value to understanding implicit organizational constructs as demonstrated here with PsyCap. Two major reasons for the past general neglect are the difficulties faced by researchers attempting to measure implicit constructs and skepticism surrounding the reliability and validity of various methods of assessing implicit constructs (LeBel \& Paunonen, 2011). We have attempted to demonstrate that these concerns can be addressed in a relatively straightforward manner using the example of implicit and explicit measures of PsyCap. We demonstrated not only that the I-PCQ is simple to develop, administer, and interpret but also that it is a valid predictor of work outcomes above and beyond the widely used self-report measure of PsyCap.

Beyond providing a needed alternative measure in the case of PsyCap, our results suggest a number of possible avenues for future researchers. Although this study focused on the implicit measurement of PsyCap, there is no reason why this method could not be utilized to assess implicit cognitive schemas surrounding other organizational behavior constructs in areas such as motivation, ethics, conflict, stress, power, politics, and leadership. Moreover, we would argue that the method used here represents a significant advance over other methods of assessing implicit constructs because it does not require coding and interpretation (e.g. TATs), the use of computers (e.g. Implicit Association Tests), or having participants rate multiple random targets (for an example, see Wood et al., 2010). Further, because such a technique could be orally presented to respondents or job applicants, it does not require even the basic literacy skills required for word-fragment completion tasks.

Besides the ease of administering this proposed implicit measurement approach, perhaps its biggest advantage over the almost universally used face-valid self-report measures is that the objective of this implicit measure is not easily discernable by the respondent. The questions do not specifically ask about the person making the ratings. Importantly, this makes implicit measures such as the I-PCQ both more "fake" resistant and less susceptible to socially desirable responding, two very big problems of commonly used self-report measures. 
Finally, motivation researchers have long argued that whereas implicit constructs are best suited to predicting important long-term outcomes, explicit measures are likely to be better predictors of shortterm tasks (McClelland et al., 1989). Although it remains to be seen whether this will hold true for the implicit and explicit measures of PsyCap, it nonetheless suggests that researchers investigating implicit constructs should not neglect usage of explicit measures. Both types of measures should be expected to contribute uniquely to the prediction of workplace outcomes.

In conclusion, we believe that the approach utilized in the construction of the I-PCQ represents an effective way to address concerns surrounding both implicit and explicit measures. Using this "Incubator" as a platform and point of departure, we look forward to organizational behavior researchers to be stimulated to try this approach to assess implicit constructs in other domains of organizational behavior, as well as rejuvenating the study and resulting theory building and effective application of PsyCap.

\section{Author biographies}

Peter D. Harms is an assistant professor of management at the University of Nebraska-Lincoln. He received his PhD from the University of Illinois. His current research interests include the assessment and development of personality, psychological well-being, and leadership.

Fred Luthans is the George Holmes University distinguished professor of management at the University of Nebraska-Lincoln. A past president of the Academy of Management and editor of three journals; his current research revolves around psychological capital and well-being.

\section{References}

Avey, J., Reichard, R., Luthans, F., \& Mhatre, K. (2011). Meta-analysis of the impact of positive psychological capital on employee attitudes, behaviors, and performance. Human Resource Development Quarterly, 22, 127-152.

Becker, W., Cropanzano, R., \& Sanfey, A. (2011). Organizational neuroscience: Taking organizational theory inside the neural black box. Journal of Management, 37, 933-961. Bennett, R., \& Robinson, S. (2000). Development of a measure of workplace deviance. Journal of Applied Psychology, 85, 349-360.

Bing, M. N., LeBreton, J. M., Davison, H. K., Migetz, D. Z., \& James, L. R. (2007). Integrating implicit and explicit social cognitions for enhanced personality assessment: A general framework for choosing measurement and statistical methods. Organizational Research Methods, 10, 346-389.

Johnson, R., \& Saboe, K. (2011). Measuring implicit traits in organizational research: Development of an indirect measure of employee implicit self-concept. Organizational Research Methods, 14, 530-547.

Latham, G., Stajkovic, A., \& Locke, E. (2010). The relevance and viability of subconscious goals in the workplace. Journal of Management, 36, 234-255.

LeBel, E., \& Paunonen, S. (2011). Sexy but often unreliable: The impact of unreliability on the replicability of experimental findings with implicit measures. Personality and Social Psychology Bulletin, 37, 570-583.

Luthans, F. (2002). The need for and meaning of positive organizational behavior. Journal of Organizational Behavior, 23, 695-706.

Luthans, F., Avolio, B., Avey, J., \& Norman, S. (2007). Positive psychological capital: Measurement and relationship with performance and satisfaction. Personnel Psychology, 60, 541-572.

Luthans, F., Youssef, C. M., \& Avolio, B. J. (2007). Psychological capital. New York, NY: Oxford University Press.

McClelland, D., Koestner, R., \& Weinberger, J. (1989).How do self-attributed and implicit motives differ? Psychological Review, 96, 690-702.

Price, J. L., \& Mueller, C. W. (1986). Handbook of organizational measurement. Marshfield, MA: Pitman.

Roberts, B. W., Harms, P. D., Smith, J., Wood, D., \& Webb, M. (2006). Methods in personality psychology. In M. Eid, \& E. Diener (Eds.), Handbook of psychological assessment: A multimethod perspective (Chap. 22, pp. 321-335). Washington, D.C.: American Psychological Association.

Schultheiss, O. C. (2008). Implicit motives. In O. P. John, R. W. Robins, \& L. A. Pervin (Eds.), Handbook of personality: Theory and research (3rd ed., pp. 603-633). New York, NY: Guilford.

Williams, L., \& Anderson, S. (1991). Job satisfaction and organizational commitment as predictors of organizational citizenship and in-role behaviors. Journal of Management, 17, 601-617.

Wood, D., Harms, P., \& Vazire, S. (2010). Perceiver effects as projective tests: What your perception of others say about you. Journal of Personality and Social Psychology, 99, 174-190.

Wright, T. A. (2003). Positive organizational behavior: An idea whose time has truly come. Journal of Organizational Behavior, 24, 437-442. 


\section{Appendix A: Harms \& Luthans Implicit Psychological Capital Questionnaire (I-PCQ)}

In the following you will see a series of three statements. Your task is to invent stories about the people in these statements. Try to imagine what is going on. Think about what happened before, who the characters are, what they are thinking and feeling, what will happen next, and how will the story end. You don't need to write the story down, just think about it until it is clear in your mind. Then respond to the items after each of the three statements using your own thoughts about what the character is thinking and feeling. Plan to spend around 2-4 minutes per story. There are no right or wrong stories. Imagine whatever kind of story you like.

\section{Someone Talks to Their Supervisor}

Remember your task is to invent a story about someone in this statement. Again, you don't need to write the story down, just think about it until it is clear in your mind. Then respond to the following items using your own thoughts about what the character is thinking and feeling. Rate the degree to which the character in your story thinks or feels using the following scale:

\begin{tabular}{|c|c|c|c|c|c|c|c|}
\hline & $\begin{array}{l}\text { The opposite } \\
\text { is very true of } \\
\text { this character }\end{array}$ & $\begin{array}{l}\text { The opposite } \\
\text { is somewhat } \\
\text { true of this } \\
\text { character }\end{array}$ & $\begin{array}{l}\text { The opposite } \\
\text { is slightly true } \\
\text { of this } \\
\text { character }\end{array}$ & $\begin{array}{l}\text { Irrelevant } \\
\text { thought/feeling } \\
\text { for this } \\
\text { character }\end{array}$ & $\begin{array}{l}\text { Slightly } \\
\text { true of this } \\
\text { character }\end{array}$ & $\begin{array}{l}\text { Somewhat } \\
\text { true of this } \\
\text { character }\end{array}$ & $\begin{array}{l}\text { Very true } \\
\text { of this } \\
\text { character }\end{array}$ \\
\hline $\begin{array}{l}\text { 1. Feeling smart } \\
\text { or intelligent }\end{array}$ & 0 & O & 0 & 0 & 0 & 0 & 0 \\
\hline $\begin{array}{l}\text { 2. Believing that } \\
\text { they can } \\
\text { accomplish their } \\
\text { goal }\end{array}$ & 0 & 0 & 0 & 0 & 0 & 0 & 0 \\
\hline $\begin{array}{l}\text { 3. Expecting good } \\
\text { things to happen } \\
\text { in the future }\end{array}$ & 0 & 0 & 0 & 0 & 0 & 0 & 0 \\
\hline $\begin{array}{l}\text { 4. Feeling } \\
\text { satisfied with their } \\
\text { life }\end{array}$ & 0 & 0 & 0 & 0 & 0 & 0 & 0 \\
\hline $\begin{array}{l}\text { 5. Being } \\
\text { concerned about } \\
\text { being seen as } \\
\text { important }\end{array}$ & 0 & 0 & 0 & 0 & 0 & 0 & 0 \\
\hline $\begin{array}{l}\text { 6. Feeling } \\
\text { accepted by } \\
\text { others }\end{array}$ & 0 & 0 & 0 & 0 & 0 & 0 & 0 \\
\hline $\begin{array}{l}\text { 7. Believing that } \\
\text { they can bounce } \\
\text { back from any } \\
\text { setbacks that } \\
\text { have occurred }\end{array}$ & 0 & 0 & 0 & 0 & 0 & 0 & 0 \\
\hline $\begin{array}{l}\text { 8. Feeling } \\
\text { confident and self- } \\
\text { assured in their } \\
\text { ability }\end{array}$ & 0 & 0 & 0 & 0 & 0 & $\mathrm{O}$ & 0 \\
\hline
\end{tabular}

Note to those using the Harms \& Luthans I-PCQ: Repeat the above exact survey items and response scale format for two additional pages with the statements at the top of: "Someone Has a New Job" and "Someone Makes a Mistake at Work". Remember that the 7-point scale ranges from -3 on the left anchor to 0 in the middle to +3 on the right anchor. The I-PCQ score is calculated from items 2 (hope), 3 (optimism), 7 (resiliency) and 8 (efficacy) from all three statements, the other four items are intended to be filler items. 